\title{
Innovation Strategy of Enterprise Human Resource Management under the Background of Big Data
}

\author{
Liu Chen ${ }^{1}$ \\ ${ }^{1}$ Capital University of Economics and Business Beijing, China
}

\begin{abstract}
With the development of social economy, the era of big data has quietly arrived. Under this background, the demand for talents of enterprises will increase, and the management of human resources in enterprises will face huge amount of data, as well as more opportunities and challenges. From the perspective of big data, this paper introduces the meaning and characteristics of big data technology, briefly analyzes various problems existing in the traditional human resource management mode under the background of big data, and expounds how to innovate with the help of big data technology, make up for deficiencies in human resource management, explore the direction of human resource reform in the era of big data, seek a new mode of human resource management in the era of big data, and use big data technology to help enterprises develop and realize economic benefits.
\end{abstract}

\section{Introduction}

Big data technology is the product of the development of information technology, which has been widely used in various fields at present. Big data technology is changing people's life and working mode. It can extract valuable data from massive and complex data resources, analyze and process it quickly, and get all the information people need. Human resource management plays a very important role in enterprise management, and advanced human resource management models can promote the development of enterprises. More and more enterprise managers have noticed that using precise human resource information can not only improve the work efficiency of human resource managers, but also effectively manage corporate employees. In the context of the era of big data, the human resource management model of enterprises should also be changed. The management concept should be updated. With the help of big data technology, the human resource management system based on big data information should be adopted to transform the traditional human resource management model into the new human resource management model pursues the innovation of human resource management model, truly and effectively play the role of human resource management, optimize enterprise management, enhance the competitiveness of enterprises, and promote the sustainable and healthy development of enterprises.

\section{The meaning and characteristics of big data}

Big data refers to a collection of data that cannot be stored, analyzed, and processed within a certain period of time with existing software in the face of massive amounts of data. In recent years, with the emergence of the Internet of Things and cloud computing, the importance of data is self-evident. As far as the current social development is concerned, big data already exists in all aspects of people's lives, such as the data of shopping preference sent by shopping software to customers in recent years, such as the urban commuting map drawn by a certain mapping software based on commuting routes of office workers. These are the results obtained after the massive collection of information through big data technology, and then sorting and analysis. Obviously, when people face massive amounts of data, what they need big data to do is to obtain, store and analyze the data in order to achieve the purpose of obtaining the value of the required information.

Big data has the characteristics of huge data volume, complex data content, diverse data types, authenticity and accuracy, fast processing speed, variable management and so on. Big data technology is the ability to quickly capture effective information from a large number of data with complex composition and various types[1]. It refers to technologies such as big data resource acquisition, storage management, mining analysis, visual presentation. The ultimate purpose of big data technology is for big data applications[2].

In order to make good use of big data, how to acquire and analyze big data is a topic that people care about. For enterprise human resource management, data acquisition, analysis and use are particularly important. In all aspects of human resource management, data is analyzed to find out the deep-level connections between various data, and even analyze the causal relationship and logical relationship between data, thus innovating the human resource management model, formulating scientific and reasonable management standards, providing personalized 
employee growth paths, enabling enterprises and employees to grow together, achieving a win-win situation and helping the healthy development of enterprises.

\section{Problems in human resource management in the era of big data}

\subsection{The traditional human resource management model restricts enterprise development}

Big data technology is a new management technology in recent years. In China, most enterprises, especially small and medium-sized enterprises, are more accustomed to using the traditional human resource management mode, which has occupied a firm position in the enterprise managers' thinking. The traditional human resource management mode mainly screens the required information manually, and this method can't dig and discover the deep connection between information like big data technology screening information. In the traditional human resource management mode, enterprise managers do not plan for long-term development in advance, and the management method is relatively primitive. Big data technology cannot be fully utilized, which is reflected in human resource management, which means that it is unable to make accurate and rapid assessments of current market development trends[3]. This kind of human resource management model shows the shortcomings of insufficient management and unsustainable development, so it is extremely urgent to change the enterprise human resource management model. Although some enterprise managers are aware of the advent of the era of big data and agree that big data analysis can improve work efficiency and promote enterprise development, managers who favor the traditional human resource management models will continue to use the traditional human resource management mode because they are worried about risks and avoid risks[4].

\subsection{Enterprise managers despise the new human resource management model}

In the management of every enterprise, the management thoughts and management concepts of the enterprise managers will influence the human resource policies formulated by the enterprise. Although more and more people have realized that big data technology has a very profound impact on human resource management, many enterprise managers do not realize that big data will have a positive impact on enterprise development in a short time, which makes these enterprise managers unwilling to adapt to the new management mode. It is precisely because these enterprise managers despise the new human resource management mode that it becomes very difficult for big data technology to change the enterprise human resource management mode.

\subsection{Human resource managers lack professional knowledge reserves}

The most valuable asset of an enterprise is talents. Because big data is a new thing, many companies lack big data talents, especially human resource managers with big data knowledge. Under the background of big data, the traditional human resource management model can no longer adapt to the development of society. If an enterprise wants to transform to a new human resource management model, it needs human resource managers with professional technical knowledge. Many companies now have no human resources staffs, and administration staff are responsible for human resource management related work part-time, so there is a lack of professional technical knowledge.

\section{Innovative strategies for enterprise human resource management in the era of big data}

\subsection{Establish the concept of big data, change from traditional human resource management concept to big data concept, make human resource management decision-making more scientific}

Big data is a brand-new way of thinking. Now that we talk about enterprise human resource management innovation in the era of big data, we must first change the traditional human resource management concepts, realize the innovation of management concepts, establish big data thinking, and guide the development of various tasks on this basis. Big data technology is not only a new thing in the technical field, but also has an important impact on people's views and ideas. Enterprise managers must always maintain a learning attitude, accept new things, accept and apply big data technology, so as to make a good integration between big data technology and human resource management, and analyze human resource data with the help of big data technology to improve the efficiency of enterprise human resource management. If corporate human resource managers want to use the opportunity of big data technology to carry out management reform and innovation, they must first recognize big data thinking, change traditional human resource management concepts and seek theoretical innovation. With the advent of the era of big data, when enterprises gradually transform from traditional human resource management methods to new human resource management methods, enterprise managers can get rid of the interference of human factors to a certain extent when making human resource-related decisions, collect and analyze human resource information through big data, investigate and match specific needs, and guide enterprise management practice with new management concepts, thus achieving the purpose of scientific decision-making of enterprise human resources. In the context of big data, the opening and sharing of data and information also gives employees more opportunities and ways to participate in 
the decision-making of the company, and the problem of unequal information between managers and employees will be gradually reduced, and enterprise human resource management will also change from enterprise management employees to the common development of enterprises and employees.

\subsection{Innovation and change of human resource management models}

Human resource management includes human resource planning, recruitment and configuration, training and development, performance management, salary and benefits management, labor relationship management. Under the traditional human resource management model, the various parts are not closely related, and the work of each part is isolated to a certain extent. In today's big data era, we can make full use of big data analysis methods to integrate and connect the information of various parts of human resource management, realize data sharing and real-time update, and form an integrated information management mode. In enterprise management, human resources, finance, assets and other departments have many intersections. There are often exchanges and transmissions of information and data between departments. Big data technology can also make information transmission between departments more convenient. Using information systems to realize information linkage can reduce the process of information collection, collation and analysis among departments, and can also avoid data inconsistency and data accuracy distortion caused by data processing by each department, thus realizing accurate data matching and data sharing.

\subsection{Independently train big data talents and build a professional human resource management team}

Under the background of big data, the level of enterprise human resources management in enterprises will gradually improve, and enterprise managers should also pay attention to the cultivation of big data talents. In addition to prioritizing job applicants with big data technology knowledge when recruiting, enterprises can also train their original employees independently, and trainings based on big data-related knowledge are regularly carried out to provide employees with a way to understand big data technology and improve their own knowledge reserve and business level[5]. In the process of recruiting talents, in addition to examining the matching degree between the candidate's ability and professional level and the job position, priority should also be given to technical personnel who understand information and data knowledge and agree with the concept of big data, so as to make sufficient preparations for enterprise information management.

\section{The impact of big data technology on all aspects of enterprise human resource management}

Big data technology has a relatively important impact on all aspects of enterprise human resource management. Combined with the background of the big data era, enterprises should set long-term development goals according to their actual conditions, apply scientific and advanced concepts to do a good job in human resource management, master all kinds of information through big data technology, and closely combine recruitment, assessment, training and development, management system and other work with big data information to improve human resource management efficiency and save human resource management costs.

\subsection{Improve the efficiency of recruitment}

Enterprises need the input of talents to ensure their good development. The recruitment of talents can be said to be the top priority of human resource management. At present, there are some shortcomings such as heavy workload and low work efficiency in the recruitment work by using traditional recruitment system. The enterprise human resources managers need to filter the duplicate information in the massive job-seeking data through the recruitment system and select the job-seeking data that accords with the intention. In this case, manual operation is prone to multi-screening and missing screening of information, which cannot guarantee the accuracy of the required job-seeking information. Big data technology can collect a large amount of job seekers' information, analyze and display the huge amount of recruitment data, so that recruiting companies can quickly and accurately screen out target job seekers who meet the requirements of the recruitment position. The recruitment platform can use big data technology to push personalized recruitment information for each job seeker based on the information such as academic degree, work experience, expected treatment, work location and the job type preference for submitting resumes. For job seekers, big data technology can be used to accurately screen out the jobs that match their expectations among the many recruitment positions on the recruitment platform according to their personal needs, so that the two-way needs of the recruitment enterprises and job seekers can be met, and the effective matching of data and information can be realized, thus improving the efficiency of recruitment work.

\subsection{Improve the assessment and evaluation system}

Nowadays, most enterprises still use the traditional human resource management model, which leads to the nonstandard evaluation of employees, and the reward and punishment mechanism established in the traditional way cannot actually meet the needs of current human resource management. Under the background of big data, enterprise managers can evaluate employees' job performance through the comprehensive evaluation data given by big 
data. When using big data to do this work, we should first ensure that the enterprise's assessment indicators are comprehensive, standardized, reasonable and scientific, and can comprehensively evaluate employees' level of business ability, contribution to the enterprise, loyalty to the enterprise, work attitude and other information[6]. The data obtained without interference from human factors will truly reflect the final results of assessment and evaluation. Using big data technology to make a comprehensive evaluation of employees can reduce the intervention of human factors, save time and cost, and reduce the workload of human resource managers.

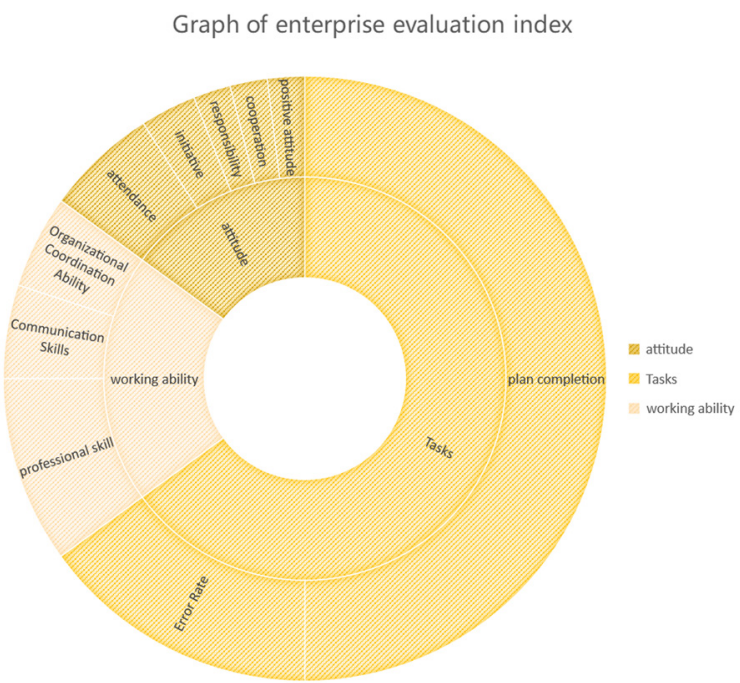

Fig 1. Graph of enterprise evaluation index

\subsection{Transition from traditional training mode to personalized training}

Training and development in human resource management is an important link to improve the quality and business ability of employees. The training of traditional human resource management models is generally where companies gather employees together and invite experts and scholars to give collective lectures or courses for employees. However, this method ignores the individual differences between employees, and not every employee needs to participate in a certain type of training, which cannot meet the individual needs of employees for training, and at the same time makes the training investment wasted. Because of the differences in their majors and the reasons for working in different positions, the fields they need to learn and improve and the content they are eager to participate in training will also be different. Big data technology can make a specific analysis of their training needs according to the data information of each employee, and give the analysis results of personalized training needs. Based on the analysis results, the enterprise human resource managers make specific and detailed plans for enterprise employees' training programs, which not only improves work efficiency, saves costs, rationally allocates training funds, but also meets the individual needs of employees.

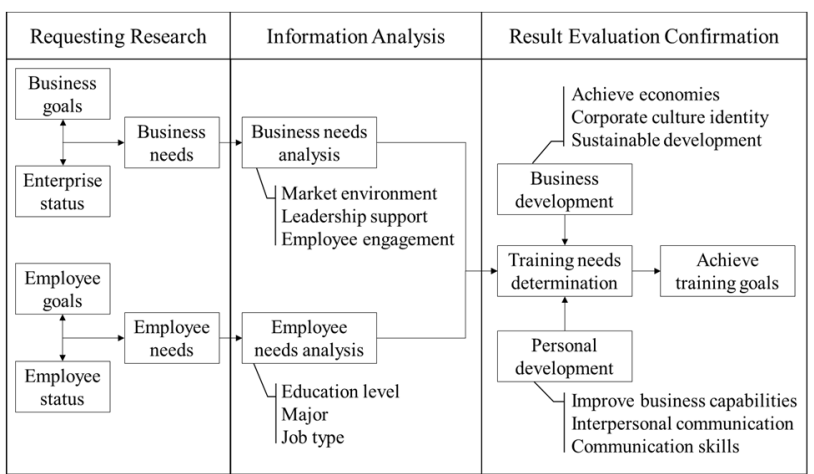

Fig 2. Graph of training needs analysis process

\subsection{Strengthen the construction of human resource management system}

Human resource management system is a necessary tool for modern enterprise human resource managers to work. It contains the full-cycle content of human resource management, such as: basic personal information, academic degree information, job change information, job title change information, entry and exit information, recruitment information, salary and welfare information, social insurance-related information. The human resource management system has changed the traditional human resource management model of looking through paper files. With the increase of employee information data and the complexity of human resources information, looking through paper files to find information data can not keep up with the times, which also makes human resource management work inefficient. The establishment of a human resource management system and the storage of complete information and data in the system database have become an urgent problem for enterprises to solve. Using a perfect human resource management system with comprehensive information and data, managers can get accurate data quickly and conveniently anytime, anywhere. Under the background of big data, enterprises rationally use big data technology to strengthen the collection and sorting of information and data, and cooperate with the human resource management system to effectively innovate the human resource management model. Therefore, the upgrading and maintenance of human resource management system should be strengthened to realize information management. Enterprises should continuously improve the human resources system. According to the characteristics of big data, integrate resources to optimize the allocation of data and information, so as to provide accurate data and forecasts for human resource management. In the process of informatization construction, enterprises should also attach importance to the development and maintenance of human resource systems, in order to maximize the use of big data technology to achieve innovation in human resource management.

\section{Conclusion}

To sum up, the traditional human resource management model in the era of big data is facing elimination because 
it can no longer adapt to the development of the times and can not provide good assistance for enterprise development. Big data technology has brought enterprise management into a new stage, which is both an opportunity and a challenge for enterprise human resource management. The new model of human resource management can increase cohesion, enhance employees' sense of belonging to the enterprise, improve the efficiency of human resource management personnel, promote the linkage of human resources work with other departments, and realize information sharing. The new model of human resource management can provide a driving force for the good development of enterprises, and transform the application of big data technology in enterprise management into economic benefits for enterprises. In the future, big data technology will develop in a wider direction, which will better serve people's lives, help managers manage enterprises, and promote social and economic development.

\section{References}

1. Wang Zheng, A Probe into the Innovation of Enterprise Human Resources Management in the Era of Big Data, Shangxun, pp.183-184,June 2020.

2. Chen Tong and Lin Jie, What is big data, Computer Knowledge and Technology, pp.10-11, May 2017.

3. Wang Xin, "The reform of human resource management from the perspective of big data era," Modern Business Trade Industry, pp.76, July 2020.

4. Chen Zhaoxi, Research on Enterprise Human Resource Management Reform Based on Big Data Era, Knowledge Economy, pp.6-8, June 2020.

5. Liang Zhemeng, "Discussion on the Reform and Innovation of Human Resource Management in Public Institutions in the Big Data Era," Money China, pp. 238-239, July 2020.

6. Hu Bin, Explore the innovation strategy of human resources performance management under the background of big data, Modern Business, pp.7273, July 2020. 